Revista Iberoamericana. Vol. LXVI, Núm. 192, Julio-Septiembre 2000, 571-586

\title{
REINSCRIBIENDO A PENÉLOPE: MUJER E IDENTIDAD MEJICANA EN COMO AGUA PARA CHOCOLATE
}

POR

Tina Escaja

The University of Vermont

“La mujer ¿esconde la muerte o la vida?, ¿en qué piensa?, ¿piensa acaso?, ¿siente de veras?, ¿'es igual a nosotros?” (Paz 79). En el intento de explorar las premisas de la identidad mejicana, Octavio Paz se detiene en el "Enigma” de la mujer (79), en su condición de otro extraño, contrario y complemento del hombre (239). Pero en esa reflexión de Paz se revela un conflicto de significados. En principio, la afirmación del “nosotros” en la cita apuntada (“¿es igual a nosotros?”) señala la condición de centro desde la que escribe y a la que se dirige Octavio Paz, un hombre en posesión del discurso hegemónico del poder, privilegio reafirmado con el galardón del Premio Nobel en 1990. Por otra parte, la clarividencia de advertir un otro disociado del yo-nosotros implica también un sentimiento de crisis y cuestionamiento que sintoniza con la condición posmoderna. En 1950, cuando Paz publica El laberinto de la soledad, premoniza la condición posmoderna en el momento en que reconoce y reflexiona sobre entidades diferenciadas y hasta entonces desestimadas por la historia. Este aspecto aparece insinuado en la cita de Antonio Machado que sirve de epígrafe al libro de Paz, en la cual se indica que, a pesar del empeño de la razón en que "lo otro no existe .... lo otro no se deja eliminar; subsiste, persiste, es el hueso duro de roer en el que la razón se deja los dientes" (7).

Sin embargo, la reflexión de Antonio Machado que evoca Paz en el epígrafe de su libro se refiere principalmente a "La esencial Heterogeneidad del ser", esto es, a "la incurable otredad que padece lo uno" (7). Esto quiere decir que las entidades al margen del poder, esos otros disociados de lo Uno, en cuanto entidades diferenciadas, siguen sin existir. La mujer, en definitiva, “nunca es dueña de sí”, concluye Octavio Paz (240).

La novela Como agua para chocolate escrita por la autora mejicana Laura Esquivel (1950) y publicada en 1989, implica una extraordinaria afirmación de la otredad en cuanto a uno diferenciado. Esta afirmación se logra a través de una múltiple redistribución jerárquica del espacio tradicional. Si tenemos en cuenta la liberación de los “diferendos” que ha supuesto la reflexión posmoderna, también habría que inferir que las nuevas voces desestimadas por la historia precisan de la creación de un nuevo centro que las legitime, esto es, precisan de la reinvención de una linealidad moderna para poder manifestarse. Y esta "nueva modernidad" no puede ser inocente desde el momento en que parte de los postulados hegemónicos para poder expresarse. Es decir, que para recrearse a sí mismos necesitan utilizar el lenguaje y el espacio del poder, que en principio ni les incluye ni les corresponde. 
El nuevo centro que plantea la novela de Laura Esquivel es el del universo tradicional de la mujer considerado hasta entonces secundario y marginal. Y el polo espacial fundamental en el que se desenvuelve Como agua para chocolate resulta sintomático: la cocina.

La cocina representa el nuevo centro de interpretación donde se crea y (re)construye la realidad, y en cierta medida, la identidad de la mujer mejicana. En la mesa de la cocina nace Tita de la Garza, protagonista de la historia, desplazando con su nacimiento el centro que le correspondía en su condición de hija legítima de los señores y dueños del rancho, descendientes de los europeos y representantes del orden patriarcal. Este primer nivel de subversión transgrede dicho orden para instaurar uno nuevo en el que participan diversos niveles de marginación tradicionalmente desatendidos. En la cocina, Tita convive con Chencha, la sirvienta campesina y analfabeta, y en particular con la india Nacha, quien cría como una madre a Tita, y como tal le transfiere la sabiduría prehispánica. En la cocina se guisa, se conjura, se amamanta, se teje, se revela el embarazo, se pare.

Sin embargo, este desplazamiento del centro al universo de la cocina no resulta unívoco sino que sistemáticamente los límites mantienen un proceso de continuo desplazamiento, de “alteración”. A través de los elementos asociados al universo de la cocina se alteran, entre otros, los límites de la casa, del cuerpo, de la geografía topográfica o histórica. En última instancia, la relatividad misma de los límites constituye la nueva linealidad propuesta por Laura Esquivel.

En el presente artículo pretendo detenerme en algunos de los diversos límites (meta)discursivos vulnerados o alterados en Como agua para chocolate. El principio de “alteración," en su múltiple alusión a lo otro o a la "alteridad”, al adulteramiento, a la exaltación o al cambio, se impone entonces como instrumento de redefinición del canon moderno, y haciéndolo, deconstruye los principios patriarcales que han definido y marginado la identidad de la mujer mejicana.

Alteración De GÉNERo TEXTUAL/SEXUAL: EL HUMOR Y LA PARODIA

La novela Como agua para chocolate viene subtitulada (o en algunas cubiertas precedida) por la rúbrica "Novela de entregas mensuales, con recetas, amores y remedios caseros”. La condición fragmentada de la historia en meses y recetas rompe desde el inicio con las expectativas de linealidad propias de una novela convencional, al tiempo que propone y legitima diversos discursos narrativos considerados marginales por el canon moderno. A esos discursos se añade y asocia el discurso y el cuerpo de la mujer, igualmente desatendido por el enunciado de la modernidad, y que legitima su espacio entre la imbricación de planteamientos propuestos por la historia de Esquivel. En último término, en el enunciado mismo de esa serie de planteamientos (entre los que se encuentran implícitas las nociones totalizadoras de alta y baja literatura; del folletín y la novela), se localiza la discrepancia, la mirada distante e irónica que celebra la multiplicidad y el fragmento frente al discurso unívoco, autoritario y masculino del poder.

Como agua para chocolate se presenta a sí misma como encrucijada de géneros populares y de asociación con lo femenino, a modo de historia de entregas (folletín/ telenovela), mensuales (menstruales), con recetas (recetario), amores (culebrón/novela rosa) y remedios (guía práctica) caseros (domésticos). Un refrán sirve de epígrafe y anticipa 
el componente erótico a la trama del best seller: "En la mesa y en la cama / Una sola vez se llama”. El refrán viene en algunas ediciones ilustrado con una cocina decimonónica, ambiente al que apela la novela y que señala al género de las revistas femeninas del XIX (de Valdés 78), anticipo de las modernas revistas para mujeres que incluyen igualmente recetas, remedios, y romances de folletín.

La estructura misma del relato responde al enunciado de subcultura popular y de calculada fragmentación. La novela se divide en doce meses/capítulos que responden a sendo número de recetas. El enunciado de ingredientes y el proceso de la receta aluden a un episodio de la vida de la protagonista, Tita de la Garza, episodio evocado a su vez por la lectura/interpretación que del recetario de Tita hace su sobrina-nieta. El proceso de la receta se alterna entonces con el del episodio evocado, creando un suspense tanto culinario como narrativo en el lector (Glenn 41). Con la culminación de la receta culmina también el episodio para anticipar una nueva crisis en la receta/capítulo inmediato (Jaffe 221). Según esto, la novela misma respondería a una receta que englobaría la crisis principal: "The narrative itself becomes a kind of recipe -a how-to book on surviving a mother's tyranny, of finding love in the midst of familial and social struggle” (Lawless 263). Este carácter de autocontención se enfatiza en la estructura circular de la historia, que invita con el final a reiniciarse nuevamente.

Según esto, el libro se inicia y concluye con la elaboración de una misma receta que responde a similar ocasión: la sobrina-nieta de Tita, narradora de la historia y alter ego de la protagonista, se dispone a cocinar "tortas de navidad” para celebrar su cumpleaños (3, 247). De igual modo, la primera receta de la historia responde también a la ocasión del dieciséis cumpleaños de Tita, vértice de la crisis principal alrededor de la cual se desarrolla la trama. En la víspera del cumpleaños de Tita se anuncia el compromiso del novio de Tita, Pedro, con su hermana Rosaura. Esa misma noche Tita concluye la colcha de su ajuar de novia que había iniciado el año anterior, desatendiendo con su tejido tanto la ley de los Garza que prohibe a Tita casarse, como la imposibilidad ulterior de sus esponsales con Pedro. Al tejido de la colcha, Tita añadirá toda serie de estambres y colores diversos, creando un caleidoscopio que refleja la fragmentación, el exceso y la parodia de los tejidos/textos propuestos en el enunciado igualmente caleidoscópico de la novela.

La elaboración de la colcha “dialógica” anticipa cronológicamente la del recetario/ diario que Tita iniciará dos capítulos más tarde (58). ${ }^{1}$ Tal anticipación al texto que fundamenta la novela supone, por una parte, la prioridad dada al género del tejido o bordado, forma primigenia de texto que además se ha atribuido tradicionalmente a la mujer. Por otra parte, la anticipación implica cierta dislocación en el proceso del relato que refleja una vez más la fractura sistemática de secuencias y expectativas en la novela, proceso que se repite a lo largo de la novela. De hecho, el enunciado mismo de un concepto o la utilización de un

\footnotetext{
${ }^{1}$ El discurso “dialógico" contrasta con el "monológico” en que reconoce el lenguaje de lo "Otro” al tiempo que celebra sus variantes. El concepto viene de Mikhail Bakhtin quien desestima el monólogo autoritario del poder en favor de lo que denomina, en traducción de David H. Richter, "carnivalization of literature” (725), un carnaval sociolingüístico en cuyos componentes de parodia, blasfemia, obscenidad, desobediencia, inversión de códigos, etc. se reconoce la estructura y temática de la novela de Esquivel alegorizadas en la colcha de Tita. El carácter "bakhtiniano” de Como agua para chocolate ha sido apuntado por Kathleen M. Glenn (42).
} 
determinado discurso en Como agua para chocolate implica con frecuencia su inmediata descalificación, apuntando con ello a las nociones posmodernas de discontinuidad, fractura y en especial “parodia” según la define Linda Hutcheon y aplica Kathleen Glenn a la novela de Esquivel: "repetition with critical distance that allows ironic signalling of difference at the very heart of similarity" (Hutcheon 26).

Los discursos “femeninos” del arte culinario, del cosido y el bordado, del manual de conducta, del romance y el melodrama, serán utilizados para subvertirse y parodiarse. Así sucederá también con los principios de literatura “seria” y popular, del lenguaje elevado y coloquial, de la jerarquía de género, clase y raza. Incluso nociones como el llamado "realismo mágico", serán replanteadas a través del humor y de la parodia. ${ }^{2}$

Josefita de la Garza, reducida familiarmente al término con que se presenta en la novela: “Tita”, constituye el eje "ex-céntrico" del replanteamiento paródico. ${ }^{3}$ Desde su condición marginada como mujer (sin derecho a opinión), hija menor (destinada a no casarse), y cocinera (asociada al mundo marginal de la cocina y de la servidumbre), Tita insiste en descalificar las reglas impuestas por Mamá Elena y el orden patriarcal que representa: “[Tita] no podía evitar la tentación de transgredir las fórmulas tan rígidas que su madre quería imponerle dentro de la cocina...y de la vida” (199). Con el cuestionamiento de la ley de los Garza, Tita pone en evidencia la precariedad de un enunciado que, al modo de las metanarrativas modernas, viene definido por su carácter absoluto e inapelable.

Según apunta Linda Hutcheon, el posmodernismo cuestiona los valores universales y transhistóricos de la modernidad, valores "no longer seen as based — as claimed — on reason or logic, but rather on a solid alliance with power .... In addition, any feeling of 'inevitability' of form was shown to be historically and culturally determined. The 'inevitable' was not eternal but learned” (26). Del mismo modo, la novela de Esquivel cuestiona muchos de los enunciados del poder considerados inapelables. Tal es el caso de la revisión que Tita hace de la ley de los Garza, exponiendo su irracionalidad o "fallas":

Sin embargo, Tita no estaba conforme. Una gran cantidad de dudas e inquietudes acudían a su mente. Por ejemplo, le agradaría tener conocimiento de quién había iniciado esa tradición familiar. Sería bueno hacerle saber a esta ingeniosa persona que en su perfecto plan para asegurar la vejez de las mujeres había una ligera falla... (10). ${ }^{4}$

\footnotetext{
${ }^{2}$ Katheleen M. Glenn afirma que "Como agua is a parodic text” (41) y pasa revista a varios de los discursos parodiados en Como agua para chocolate como el folletín o el melodrama. Según Glenn, "[the] lack of verisimilitude, hyperbolic language and set phrases, melodramatic tone are ... deliberate strategies employed to emphasize the ironic distance that exists between Esquivel's text and the formulaic ones she recasts” (43). El planteamiento paródico de Como agua para chocolate ha sido apuntado por otras críticas como María Elena de Valdés, Janice Jaffe, y también Kristine Ibsen, quien se detiene en la utilización paródica del "realismo mágico" en la novela de Esquivel.

${ }^{3}$ Linda Hutcheon identifica lo que denomina "Ex-centric" con "those who are marginalized by a dominant ideology" y de quienes "parody appears to have become . . . the mode" (35). Tal es el caso de la relación de Tita con el poder de Mamá Elena, si bien su "ex-centricidad” se relocaliza en el nuevo centro de la cocina explorado por Esquivel. La condición “ex-céntrica” de Tita y de la novela podría extenderse, como indica Glenn, a la geográfica de México y a la propia Laura Esquivel (44, n5).

${ }^{4}$ Otro ejemplo de cuestionamiento de los valores absolutos es el axioma presentado más tarde por Gertrudis: "La mera verdad es que la verdad no existe" (190).
} 
Asimismo, Tita cuestiona — al tiempo que predica — las reglas del manual de Carreño (57); altera los ingredientes de sus recetas después de advertir los peligros de hacerlo (45, 47); relata la historia de Gertrudis inmediatamente después de la prohibición de nombrarla en la casa (58); califica el episodio de su hermana como “liberación” cuando las convenciones la descalifican como ofensa (56).

Por su parte, Pedro se casa con Rosaura "sintiendo un inmenso e imperecedero amor por Tita” (14). Gertrudis se preocupa por el almíbar de sus torrejas en medio del melodrama del presunto embarazo de Tita (190). El emotivo encuentro entre Chencha y Tita, tras medio año de reclusión de la última en casa de John, "fue breve, para evitar que el caldo se enfriara" (124).

El humor funciona a su vez como mecanismo paródico en una doble acepción del término. Por una parte, el sentido etimológico del latín humor alude a los fluidos corporales que desde la antigüedad categorizaban físicamente a las personas. En este sentido, la obra de Esquivel da prioridad al discurso del cuerpo, sus necesidades y secreciones, frente al discurso artificial de las convenciones morales. Además del planteamiento gastronómico de la historia, la novela abunda en referencias a funciones corporales consideradas tradicionalmente inferiores o tabú. Según esto, la novela presenta equivalencias entre la necesidad de orinar, saciar la sed y hacer el amor (98); entre la menstruación y la liberación (200); entre la escatología y la presentación antagónica de un personaje como Rosaura.

Derivada de la acepción etimológica humor es la asociación popular del humor al estado de ánimo (estar de "buen” o de "mal” humor) y también la relación entre el humor y lo cómico, lo que produce la risa. Esta acepción convive con la previa en el título mismo de la novela en el que revierten ambos conceptos del humor. La expresión “como agua para chocolate” asocia el significado literal, estar el agua en ebullición, con el sentimiento de fastidio e irritación, pero también alude tangencialmente al deseo sexual. La relación entre la sustancia (el líquido en ebullición), y la carne (la persona excitada), se extiende a la parodia cuando se presenta como legítimo enunciado de un texto literario. Las variantes de asociación a los fluidos corporales en la obra de Esquivel conviven entonces con la parodia de una serie de discursos planteados desde su mismo enunciado (histórico, popular, gastronómico, panfletario) a través del mecanismo purgante de la risa, del humor. Asimismo, la supuesta utilización del llamado "realismo mágico" extiende los significados del humor a una última connotación, aquella del exceso, el capricho y la fantasía que en la novela revierte en lo culinario. ${ }^{5}$

Las convenciones narrativas se subvierten entonces a partir de su propia utilización. El humor y la parodia revisan la alusión romántica del amor ideal que representa el sentimiento entre Tita y Pedro, mediante registros escatológicos o alusiones a fluidos y especias. Asimismo, el final de la historia no se produce al modo del cuento de hadas insinuado en esa relación amorosa: la historia de amor acaba en boda, pero no es la de Tita y Pedro; el "colorín colorado” con que suelen concluir los cuentos no puede darse porque la historia, en realidad, ni se resuelve ni termina. Por el contrario, el exceso y lo dialógico se impone en la novela a modo de fuegos de artificio con los que parece imponerse a su vez

\footnotetext{
${ }^{5}$ La vinculación entre el humor y la fantasía, más evidente en la acepción italiana del término: "umore", ha sido destacada por Luigi Pirandello en su trabajo sobre el tema.
} 
la cocina sobre el resto de la casa, carbonizándola en un climático final con que culmina el exceso culinario presentado a lo largo de la historia.

El resultado es un producto dialógico que incorpora múltiples discursos para el consumo de paladares diversos. El éxito comercial de Como agua para chocolate invade el territorio universitario, culinario, geográfico. La novela se incorpora a los requisitos académicos, se discute en convenciones e inspira artículos como el presente. Las recetas se anuncian y cocinan en restaurantes. El best seller se presenta en la edición española de Anchor Books como "Nacional”, y en su edición gemela en inglés, como "National”. En la duplicación se insinúa el interés por la apropiación territorial al tiempo que implica la asociación de dos países, Méjico y EEUU, así como la realidad bilingüe y culturalmente heterogénea de EEUU. Y sin embargo, esa ruptura fronteriza en función de la comercialización del texto, ruptura que coincide con la fluidez de fronteras característica del período en que se desarrolla la historia de Esquivel, queda invalidada por la barrera que en realidad existe entre ambas culturas. ${ }^{6}$ En este sentido, el carnaval de profanaciones y guiños paródicos alcanza el aspecto social y editorial, mostrando también los supuestos peligros del intercambio cultural que parecen imponerse sobre el cuestionamiento de los límites planteados por la novela. En los preliminares a Como agua para chocolate, la edición tanto española como inglesa de la editora "americana” Anchor Books advierte: "Las recetas en este libro son recetas tradicionales mexicanas que no han sido probadas por el editor”.

\section{Alteración DEL ESPACIO CORPORAL: LA TRANSUBSTANCIACIÓN}

Desde el momento en que la india Nacha, cocinera de la familia de los Garza, determina "formarle el estómago" a Tita (5), la identidad de la hija menor de los propietarios del rancho se asociará al universo maravilloso de la cocina. Sobre este territorio Tita ejercerá dominio absoluto frente a aquél de Mamá Elena, su oponente en el control de los destinos de los habitantes del rancho. El territorio externo de la casa, asociado al artificio de las convenciones burguesas, será sustituido entonces por el territorio natural de los "humores”, en un sentido múltiple de apelación a los fluidos corporales, al estado de ánimo, a lo cómico y al exceso de lo maravilloso. La consanguinidad que relaciona Tita con los Garza se altera para establecer un nuevo vínculo con la cultura prehispánica desde el territorio femenino y culinario, cultura que Tita adopta e incluso anticipa con su espectacular nacimiento.

Desde el principio de la historia, el exceso y lo maravilloso se asocian casi exclusivamente con Tita. Con el residuo de las lágrimas que vierte Tita cuando nace, se "rellenó un costal de cinco kilos que utilizaron para cocinar por bastante tiempo" (4). Su segundo nacimiento, es decir, el que se produce tras el enfrentamiento de Tita con su madre y posterior convalecencia en casa de John, también se caracteriza por las lágrimas que corren como un riachuelo desde el cuarto donde Tita recupera su voz e identidad (124-25). Asimismo, Tita es el único personaje que presencia y dialoga con espíritus y que recupera la memoria ancestral mediante la comida y los remedios caseros. Las recetas que prepara poseen

${ }^{6}$ De Valdés dice: "the way of life along the Mexican-U.S. border from the 1850 s to the narrative time of 1895-1934 was a period of constant border-crossing... It is only in the post-World War II era that the border has become a barrier” (de Valdés 82, n6). 
también cualidades que llegan a alterar radicalmente los acontecimientos, como la huida de Gertrudis o las reacciones de los comensales a las respectivas celebraciones que se suceden a lo largo de la obra: la vomitona el día de la boda de Rosaura con Pedro (37-39); la euforia en el bautizo de Roberto (81); el desenfreno pasional en los esponsales de Esperanza y Alex (242-43).

Del mismo modo, la palabra que enuncia Tita, y que se ejerce desde el territorio de la degustación (la boca), adquiere una función demiúrgica equiparable al poder de creación e interpretación de los sentimientos y deseos de Tita conjurados por los guisos. Así sucede con los deseos que Tita enuncia ante el muñeco de porcelana de la rosca de reyes, la mayoría de los cuales se harán realidad: “Ojalá que su madre dejara de atormentarla .... ¡Ojalá que Esperanza se casara .... ¡Ojalá que Gertrudis regresara a casa ...” (175-76). Lo mismo sucede cuando "involuntariamente" Tita ensarta una maldición contra su hermana: Cuando Rosaura insiste en repetir el destino de Tita en su hija Esperanza, la irritación de Tita le hace desear que su hermana "nunca hubiera dejado escapar esas repugnantes, malolientes, incoherentes, pestilentes, indecentes y repelentes palabras. Mas valía que se las hubiera tragado y guardado en el fondo de sus entrañas hasta que se le pudrieran y agusanaran" (15051). Como sabemos, Rosaura muere de forma maloliente y grotesca por "congestión estomacal aguda” (233). ${ }^{7}$

El poder demiúrgico que Tita ejerce desde el universo de la cocina llega a imponerse sobre aquel de la patria potestas ejercida pero también usurpada por Mamá Elena. Mamá Elena usurpa el territorio patriarcal al ejercer la autoridad desde su condición de mujer, que además pretende excluir al hombre: "Nunca lo he necesitado para nada [un hombre], sola he podido con el rancho y con mis hijas. Los hombres no son tan importantes para vivir padre —recalcó- - Ni la revolución es tan peligrosa como la pintan” (82). Asimismo, Mamá Elena transgrede los límites convencionales morales, de clase y de raza al haber mantenido relaciones adúlteras con un mulato de origen esclavo. La falsificación del discurso de Mamá Elena implica, por lo tanto, la negación sistemática de los enunciados que propone. Como sabemos, la realidad contradice las palabras de Mamá Elena a propósito de la revolución (ella misma será víctima del desorden revolucionario al ser atacada por unos bandoleros); su disposición contra Tita apenas tiene efecto (no logra evitar su relación con Pedro); sus pronósticos y maldiciones tampoco, como las que formula en contra del presunto hijo de Tita: “¡Lo maldigo yo! ¡A él y a ti, para siempre!” (173). Una vez que enfrenta la ilegalidad del modelo propuesto por Mamá Elena, Tita logra exorcizar tanto el fantasma de su madre muerta como la relación de dependencia con la misma:

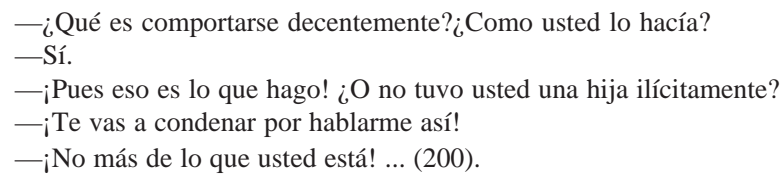

\footnotetext{
${ }^{7}$ También Pedro, como Tita, demuestra una coherencia absoluta con las palabras que pronuncia. Su afirmación del inicio de la historia se mantendrá hasta el final de la misma: "yo soy hombre de pocas, pero muy firmes palabras. Le juro que tendrá mi amor por siempre” (17).
} 
Igual que sucede con Mamá Elena, los juicios de Rosaura tampoco tienen consecuencia alguna en el desarrollo de la historia: La determinación de Rosaura de alejar a Esperanza de la influencia de Tita resulta vano (215); su intención de mantener el control sobre la educación de su hija también resulta infructuosa (238).

Por el contrario, Tita ejerce un domino casi absoluto sobre las asociaciones y destinos de los miembros del rancho. En el momento en que se casa con Pedro, Rosaura —quien se había presentado negativamente por su vinculación a Mamá Elena, su desprecio a la cocina y su desinterés por la comida—, se asocia a la náusea y al desarreglo gástrico. La ingestión del pastel nupcial, intoxicado por las lágrimas de Tita con las que la muchacha transfiere su frustración y náusea, crea una vomitona general entre los comensales a la que se integra de forma espectacular la novia, Rosaura: "no hubo un solo pedazo de su vestido que quedara libre de vómito. Un voluminoso río macilento la envolvió y la arrastró unos metros, provocando que sin poder resistir más lanzara como un volcán en erupción estruendosas bocanadas de vómito” (38-39). Sin embargo, cuando Rosaura escapa a la influencia de Tita recupera su cuerpo e identidad, para volver a caer con su proximidad en el dominio culinario de Tita hasta el extremo apuntado de la muerte: "Tita se sorprendió al verla. Estaba igual de delgada que cuando era soltera... Lo mismo le había pasado cuando se habían ido a vivir a San Antonio: adelgazó rápidamente, pero no hacía más que regresar al rancho y ¡a engordar!” (213).

También Mamá Elena sufre las consecuencias de la transferencia de los deseos y sentimientos de Tita a la comida. Mamá Elena, inválida tras el encuentro con los bandoleros, insiste en reconocer un sabor amargo en la comida que le prepara Tita (132). Mamá Elena está convencida de que Tita pretende envenenarla y decide compensar los presuntos efectos del veneno con un fuerte vomitivo (136). Este remedio acabará verificando el pronóstico de Mamá Elena, esto es, el abuso del vomitivo acabará, propiamente, por envenenarla (136).

El principio de la transubstanciación se mantendrá a lo largo de la historia, transmutando identidades y condicionando caracteres y eventos. ${ }^{8}$ Según esto, el cuerpo de Tita se consustancia en diversas ocasiones con el de Nacha, en el que a la vez conviven generaciones de tradición indígena: “Tal parecía que era la misma Nacha la que en el cuerpo de Tita realizaba todas estas actividades" (48). La mirada voluptuosa de Pedro transforma los senos vírgenes de Tita “de castos a voluptuosos” (67). Ese encuentro visual, sublimado en el relato a un encuentro sexual, anticipa la capacidad maravillosa de Tita de amamantar a Roberto, el hijo de Pedro y Rosaura (77). El deseo permanente de Tita de procurar alimento, —y con ello indirectamente mantener el control sobre los comensales- logra leche de sus senos que a su vez habían sido transformados por la comunión visual con Pedro en la cocina. Por lo mismo, Tita ejerce de madre de Roberto al haberle dado a luz (facilitó el alumbramiento del bebé); al amamantarlo (la madre biológica no puede hacerlo); al sustituir a Rosaura en el banquete del bautizo; al constituir Roberto, en definitiva, el resultado del amor entre Pedro y Tita.

${ }^{8}$ La "transubstanciación” viene definida en el diccionario de María Moliner como la acción de "transubstanciarse" o "convertirse totalmente una substancia en otra", y se refiere a la transformación del pan y del vino de la Eucaristía en el cuerpo y la sangre de Cristo (1366). El término “consustanciación” refiere a la variante luterana: “la sangre y el cuerpo de Jesucristo están en la Eucaristía sin que, por ello, ésta deje de ser pan y vino” (739). 
Una transferencia similar se produce en la relación de Tita con Esperanza, también hija de Rosaura y Pedro. Las dos comparten circunstancias similares que las vinculan o duplican. Ambas son hijas menores y como tales comparten un mismo destino en la tradición de los Garza (147); las dos nacen prematuramente y se vinculan a una muerte en la familia (146); las dos deben criarse en la cocina, con tés y atoles, que las asocia a la tradición prehispánica, en vez de alimentarse con la leche materna que implica la tradición patriarcal y europea de Mamá Elena/Rosaura (147).

Al mismo tiempo, Tita ejerce de Nacha al “formar el estómago” a Esperanza y con ello formar la identidad de la niña en función del universo de la cocina. En el espacio uterino de la cocina, "paradisíaco y cálido” (147), locus de la creatividad y de la reconstrucción del orden externo, Tita construye a Esperanza y se autoconstruye al mismo tiempo; libera a la ahijada y se libera a sí misma al nombrarla "Esperanza”. En último término, Tita se transfiere a la hija de Esperanza quien contará la historia de su tía abuela desde dicha asociación: “yo soy igual de sensible que Tita, mi tía abuela” (3, 247).

La comida funciona entonces como territorio de reconstrucción del orden impuesto por Mamá Elena y las convenciones patriarcales, orden heredado por Rosaura, alter ego de Mamá Elena. Al mismo tiempo, la comida ejerce de significante de los sentimientos de Tita de frustración, euforia, castración o deseo. ${ }^{9}$ No sólo los sentimientos de Tita se reconocen en la comida y se transfieren a ella, sino también el cuerpo de Tita se transubstancia en los guisos. El ejemplo más notable del principio de transubstanciación es el episodio clave de las "codornices con pétalos de rosas".

Al principio del episodio se establece la advertencia que invita implícitamente a su transgresión:

Se desprenden con mucho cuidado lo pétalos de las rosas, procurando no pincharse los dedos, pues aparte de que es muy doloroso (el piquete), los pétalos pueden quedar impregnados de sangre y esto, aparte de alterar el sabor del platillo, puede provocar reacciones químicas, por demás peligrosas. (45, énfasis mío).

Tita, cocinera experta y cuidadosa, desatiende ostentosamente el enunciado: “Tita apretaba las rosas con tal fuerza contra su pecho que, cuando llegó a la cocina, las rosas, que en un principio eran de color rosado, ya se habían vuelto rojas por la sangre de las manos y el pecho de Tita” (47). Las reacciones de los comensales a la poderosa alquimia resultan consecuentes a la percepción que de los personajes tiene Tita (y la narradora): Rosaura siente o finge náuseas (50);. Mamá Elena, por hipocresía o antagonismo hacia Tita, decide que tiene "demasiada sal” (50); Tita se ausenta de su cuerpo para transferirse a las codornices y activamente penetrar el cuerpo de Pedro, quien lo recibe en éxtasis amoroso (51);

\footnotetext{
${ }^{9}$ Los ejemplos de asociación de los sentimientos de Tita con la comida son numerosos, empezando con el título de la novela que, entre otras asociaciones, relaciona el agua en ebullición con la irritación de Tita: “Tita literalmente estaba como agua para chocolate. Se sentía de lo más irritable” (151). Otro ejemplo significativo en la novela es la identificación de la frustración sexual de Tita con el último "chile en nogada" en un banquete, delicia que se evita comer por razones de etiqueta: "¡Se sentía tan sola y abandonada!.... ¡un maravilloso chile en nogada ${ }_{i}$ Que contiene en su interior todos los secretos del amor, pero que nadie podrá desentrañar a causa de la decencia” (56-57).
} 
Gertrudis sintetiza la relación sexual entre ambos: "Parecía que habían descubierto un código nuevo de comunicación en el que Tita era la emisora, Pedro el receptor y Gertrudis la afortunada en quien se sintetizaba esta singular relación sexual, a través de la comida” (51).

La función de intermediaria de Gertrudis en los amores de Pedro y Tita se mantendrá a lo largo de la novela. En la cama de Gertrudis, Pedro y Tita consumarán su amor (159) y en ella mantendrán sus encuentros sexuales clandestinos. Asimismo, Gertrudis facilita la revelación de Tita a Pedro sobre su embarazo (191); sugiere métodos anticonceptivos (203); refleja, en definitiva, el subconsciente sexual de Tita. El desenfreno y la exposición del cuerpo de Gertrudis contrasta entonces con el recato y la inhibición de Rosaura, en una presentación maniquea que evoca los cuentos de hadas y que conveniente (y cómicamente) Tita enfatiza a través del poder de sus guisos. ${ }^{10}$

Tita se sitúa deliberadamente entre ambos términos, se relocaliza en un nuevo orden sobre el que ejerce como Deus ex machina del entramado gastronómico y así lograr en último término su aspiración: consumar su amor por Pedro y "obtener el derecho de determinar su propia vida” (168). Paradójicamente, este último enunciado no se verificará, y todo su deseo mantendrá el carácter secreto del universo marginal en el que se presenta. Laura Esquivel será la que desvele esa posibilidad tradicionalmente ocultada, al tiempo que contradictoriamente reafirma el principio patriarcal de la cocina como lugar de reclusión. Sin embargo, precisamente por la ruptura sistemática de expectativas presentada en la novela y por el éxito comercial de la historia, la cocina también se expone como lugar de poder, de creatividad y de liberación de la identidad de la mujer mejicana.

Alteración de los arquetipos de la femineidad:

Malinche, Guadalupe, Penélope “Re-Visados”

En la "galería de retratos femeninos” de la literatura mejicana, Rosario Castellanos denuncia la escasez, superficialidad y secundariedad de la mujer, quien con frecuencia ha quedado reducida a un trazo (227-28). Entre los estereotipos femeninos mejicanos, Castellanos destaca las figuras de "la madre, con su capacidad inagotable de sacrificio; la esposa, sólida, inamovible, leal; la novia casta; la prostituta avergonzada de su condición y dispuesta a las mayores humillaciones con tal de redimirse” (228). Por su parte, Luis Leal divide los arquetipos de la mujer mejicana en dos grupos: "that of the woman who has kept her virginity and that of the one who has lost it” (227). Representante aglutinador del primer grupo sería la Virgen mestiza de Guadalupe que se asocia a la novia virgen e intocable, y especialmente a la madre: "humble, obedient, unpretentious, quiet, faithful, and submissive" (Leal 153). Representante del segundo es la Malinche, amante e intérprete de Hernán Cortés

\footnotetext{
${ }^{10}$ Como se indicó más arriba, uno de los modelos parodiados en Como agua para chocolate es el del cuento de hadas. Con frecuencia, la retórica empleada por Esquivel evoca la de las historias infantiles: “Tita pronunció las palabras mágicas para hacer desaparecer a Mamá Elena para siempre” (200); “Pedro golpeó su copa con la de los demás con tal fuerza que la rompió en mil pedazos” (157). La relación específica entre la historia de Esquivel y el cuento de Cenicienta ha sido apuntada por María Elena de Valdés (81) y Kathleen Glenn (44-45).
} 
que reaparece en la psique mejicana como "la Chingada", la mujer a un tiempo traidora y violada que se reconoce en el mito de Eva y se asocia a la "Madre violada” (Paz 103), a la desvirgada, a la prostituta.

Como agua para chocolate cuestiona y subvierte muchos de los arquetipos apuntados. Por una parte, la obra de Esquivel inserta la mujer mejicana en un discurso oficial que tradicionalmente la ha ignorado o reducido a un esquema. ${ }^{11} \mathrm{Al}$ mismo tiempo, la novela problematiza las figuras tradicionales de la madre pasiva y sumisa, de la novia intocable, de la admirada esposa, de la prostituta arrepentida. La galería que propone Esquivel descalifica esas nociones al tiempo que pone en evidencia la posibilidad de una doble lectura de la presentación tradicional.

En principio, la novela desplaza al fondo de la historia una lectura oficial que coincide con los parámetros tradicionales y que vendrían a identificarse con las "buenas costumbres" canonizadas en el manual de Carreño y representadas por Mamá Elena/Rosaura. Al mismo tiempo, el enfoque de la novela los cuestiona: Mamá Elena es una madre que abusa y degrada en nombre del "Estado"; Tita es la novia maravillosa de dos hombres, con uno de los cuales mantiene relaciones sexuales sin detrimento del amor del segundo; Rosaura es la esposa que al obedecer a la madre usurpa el puesto de la hermana, y cuya fidelidad y “decencia” se descalifica sistemáticamente presentándose como figura absurda y grotesca; Gertrudis se libera con el oficio de prostituta y se legitima como soldadera y generala de las tropas rebeldes. La figura de la Malinche se altera y cuestiona entonces, desafiando con ello las definiciones masculinistas que la han vinculado a la misógina alegoría nacional, mito a que ha contribuido el ensayo de Octavio Paz con el que se iniciaba este estudio.

Para Octavio Paz, la Malinche representa el origen del desarraigo nacional (105), el rechazo a la tradición indígena en favor del blanco extranjero que fascina, seduce y viola a la india (104). En la novela de Esquivel, si bien Tita de la Garza es quien traiciona la tradición al desobedecer a la madre y la ley que representa, es Mamá Elena quien ejerce de una Malinche "a la inversa” al tratarse de la blanca criolla seducida por el mestizo extranjero. Esta traición de Mamá Elena pone en evidencia la falsificación del discurso oficial que ella representa, un poder que en último término expone la condición dependiente y supuestamente "chingada" de la colonia frente a los valores patrios (indigenistas) de la revolución a que se asocia la rebeldía de Tita. En último término, Tita se yergue como estandarte de la revolución y la Reforma al negar a la Madre y, haciéndolo, romper con la tradición que ella encarna. Esta "negación de la Madre" paradójicamente coincide con los postulados excluyentes formulados por Octavio Paz (105-06).

De hecho, la autoridad de Mamá Elena sobre Tita queda descalificada desde el planteamiento mismo de la historia. Al inicio de la novela se explica que a Mamá Elena, debido a la impresión causada por la muerte de su marido, "se le fue la leche” (4). Mamá Elena no puede entonces "amamantar" a Tita, es decir, no puede ejercer propiamente de

\footnotetext{
${ }^{11}$ La galería de personajes femeninos en la novela de Esquivel es muy rica. En contraste con la multitud y complejidad de muchas de las mujeres de la novela, los hombres con cierta relevancia son muy pocos y apenas son esbozados por la protagonista, Tita de la Garza, y por su alter ego Esperanza, la narradora de la historia. Tal es el caso de Pedro, cuya personalidad carece de relieve, y de John Brown, figura algo más compleja debido quizás a su presentación ambigua, en cierto modo "feminizada".
} 
“madre” y delega a Nacha la función de “formarle el estómago” a la niña mientras ella ejerce la función masculina del manejo del rancho(5). Pero cuando muere Mamá Elena descubrimos que la forzosa redistribución que constituye la base del conflicto en la novela y la relocalización de Tita en el universo de la cocina, ha sido motivada indirectamente por Mamá Elena. Juan de la Garza, marido de Mamá Elena y padre de Tita, murió de un infarto al enterarse de los amores adúlteros de su mujer y la ilegitimidad de Gertrudis (139). Mamá Elena, por lo tanto, determina el destino de Tita al darle a luz en la cocina e imponer su condición de hija menor. La insistencia de Tita en realizar su amor por Pedro consiste entonces en un esfuerzo por cuestionar el orden oficial usurpado por Mamá Elena y legitimar la razón y el derecho superior encarnado por la ley natural al amor y a la reproducción. Al mismo tiempo, Tita reivindica un nuevo y verdadero orden integrado por el discurso precolombino heredado de su madre adoptiva, la india Nacha.

La condición secreta, femenina, del malinchismo de Mamá Elena convive entonces con su actitud externa, masculina, que responde a la violencia propia del término "chingar”. Para Octavio Paz, “chingar es hacer violencia sobre otro. Es un verbo masculino, activo, cruel; pica, hiere, desgarra, mancha. Y provoca una amarga, resentida satisfacción en el que lo ejecuta” (93). En palabras de Tita, Mamá Elena es experta en “partir, desmantelar, desmembrar, desolar, destetar, desjarretar, desbaratar o desmadrar algo”(97). Esta duplicidad en el personaje de Mama Elena llega a neutralizarse al sufrir en sí mismo las consecuencias del desorden causado por la revolución. El rancho de la familia de La Garza será atacado por unos bandoleros oportunistas y Mamá Elena, “al tratar de defender su honor, recibió un fuerte golpe en la espalda” (130) que la deja significativamente inmovilizada de cintura para abajo. Como consecuencia del ataque, la autoridad de Mamá Elena se ve apenas reducida a la extensión de su propio cuerpo, sobre el que ejerce la violencia hasta el punto de morir por abuso de ingestión de vomitivos. Sin embargo, Mamá Elena logra con su muerte mantener su integridad discursiva al haber prevalecido su oposición a la voluntad de Tita y restaurar así el orden patriarcal que hubiera sido roto de haberse casado Tita en vida de la madre.

En este sentido, resulta interesante advertir que no es hasta que muere Mamá Elena que Tita descubre la duplicidad de la madre. Preparando a Mamá Elena para el velorio, Tita "le quitó de la cintura el enorme llavero que como una cadena la había acompañado desde que ella recordaba .... Pero además del enorme llavero, tenía colgado al cuello un pequeño dije en forma de corazón y dentro de él había una pequeña llave” (137). La llave corresponde a un pequeño cofre donde Mamá Elena escondía su diario y unas cartas que revelan su amor secreto por José Treviño, el amante mulato de Mamá Elena y verdadero padre de Gertrudis. El llavero que lleva colgado Mamá Elena como una cadena simboliza los atributos masculinos que usurpa y ejerce la madre y que señalan a la historia oficial. El dije y cofre secretos simbolizan por su parte la condición vaginal, femenina, de la historia verdadera de Mamá Elena. Tita simpatiza con la segunda, identidad a la que llora y con quien se identifica por su cualidad marginal y víctima que asimismo experimentó “un amor frustrado” (139).

La india Chencha es otro de los personajes de la novela que revisan la figura de la Malinche. La capacidad de Chencha de mentir, esto es, de crear historias, transciende el personaje tradicional de la sirvienta chismosa y parlanchina. Asimismo, esta capacidad creativa le permite mantener una continua transgresión de las normas que en último término 
la señalan como mediadora entre las barreras morales y físicas presentadas en la novela. Según esto, Chencha desobedece con frecuencia a la patrona; simpatiza con la antiheroína, Tita; lee cartas ajenas; aparece como informante y conexión entre Gertrudis y Tita [le entrega una carta de la primera a la hermana (126)], y entre Tita y Mamá Elena [debe comunicar a la madre la decisión de la hija de no regresar al rancho (126)]. El continuo y natural traspaso de Chencha de las fronteras entre EEUU y México (126-27) funcionaría entonces como metáfora de la fluidez de fronteras normativas transitadas por Chencha, fluidez que ella facilita a los menesterosos de la historia (en particular a Tita). En este sentido, la capacidad salvadora de Chencha resulta lugar común en la novela: Chencha "resucita" a Tita con su caldo de colita de res (123); como una "bendición” anuncia la cena en el momento de mayor tensión entre los comensales (157); regresa al rancho, como “caída del cielo”, cuando Tita más lo necesita (152). La cualidad creativa, mediadora y salvadora de Chencha reivindica entonces a la Malinche, la india igualmente violada y considerada desobediente y traidora. Esa cualidad visionaria y mediadora de la Malinche ha sido reivindicada asimismo por autoras chicanas contemporáneas, quienes ven en la Malinche “a feminine Messiah” (Ordóñez 326) “a synthesis of North American as well as Mexican culture” (Ordóñez 318-319).

Pero el principal personaje de Esquivel en el que converge el arquetipo de la Malinche es Gertrudis. Gertrudis, en su condición genérica (y literal) de "hijo de la Chingada", representa propiamente el discurso de la revolución según la afirmación de Paz (90). No obstante, su condición de mujer multiplica la marginalidad del personaje. Gertrudis no es sólo "hijo de la Chingada" sino la Malinche misma. Gertrudis es bastarda, mulata y prostituta. Vive como soldadera, al margen de la revolución y desde la revolución misma. Pero esta extremación de la condición marginal de Gertrudis lejos de vituperarse o ignorarse, como solía hacerse en la historia oficial, se celebra en la novela y se asocia a la protagonista, Tita. De hecho, la condición subversiva de Gertrudis, representante de la revolución, finaliza legitimándose en una triple vertiente: mediante el matrimonio con su primer amor; mediante la legitimación de su propia identidad al tener un hijo mulato dentro del matrimonio; y, finalmente, a través del reconocimiento social y del poder económico:

Gertrudis llegó a la boda de Esperanza y Alex en un coupé Ford “T”, de los primeros que sacaron con velocidades .... [Juan] lucía un elegante traje ajustado, sombrero de carrete y polainas. El hijo mayor de ambos, se había convertido en un mulato escultural .... El color de la piel era la herencia de su abuelo y los ojos azules la de Mamá Elena (235).

Esto es, con el triunfo final de Gertrudis supuestamente se constituye el orden ideal del México postrevolucionario, que no necesariamente la liberación personal de Gertrudis como arquetipo de la mujer mejicana. Con el mesianismo postrevolucionario se restituyen los valores patriarcales desatendidos durante la revolución, valores que excluyen a la mujer de la historia oficial y de la literatura canónica (Franco 188). El desajuste de Gertrudis (antes liberada de trajes y ornamentos, hábil generala y jinete consumado), parece insinuarse en la torpeza y el porte grotesco con que ejerce el nuevo rol, torpeza y exceso que contrasta con la elegancia impecable de Juan: "[Gertrudis] al bajarse del auto por poco se le cae el gran sombrero de ala ancha con plumas de avestruz que portaba” (235). 
Entre los dos extremos apuntados — por un lado el conservador de Mamá Elena y su representante y alter ego, Rosaura; por otro el de Gertrudis y la revolución con que simpatiza la protagonista y el texto- - Tita se sitúa en un término medio o en cualquier caso diverso de los propuestos. Tita, localizada en el nuevo centro de la cocina, se apropia de un discurso diferente que no es el blanco de Mamá Elena ni el mestizo de Gertrudis sino que se trata del discurso heredado de la nueva y verdadera madre, la india Nacha. De este modo, Tita rescata e incorpora en sí misma el discurso precolombino en el que conviven la sabiduría oral y lo real maravilloso.

Como se indicó más arriba, el exceso y lo maravilloso se asocian casi exclusivamente con Tita. Su capacidad y autoridad creadora en el universo de la cocina llega incluso al extremo de lograr que ella misma amamante al hijo de su hermana desde su condición virgen. En este sentido, Tita ejerce de Virgen Madre a modo de otro arquetipo de la mujer mejicana, la Virgen de Guadalupe. En la novela, Tita se presenta como la proveedora que alimenta al hambriento y protege al desamparado (77). Esta imagen virginal se enfatiza visualmente en la película: frente a la ventana en casa de John, la convaleciente Tita irradia paz y luz al modo de la virgen mestiza en la iconografía popular. Y al tiempo que Tita ejerce de Virgen protectora y de madre pura y entregada, Tita se presenta también como la mujer agredida, la mujer violentada no sólo por la agresividad masculinizada de la madre sino también por la fuerza literal del macho, como se ejemplifica en el episodio del primer “encuentro" sexual de Tita y Pedro (159).

Receptora de la tradición, Laura Esquivel, a través de la protagonista de su novela, la reinterpreta y reconstruye a partir del universo de la cocina y del cuerpo de la mujer. Su acto de "re-visión", en la acepción propuesta por Adrienne Rich, ${ }^{12}$ se extiende a otros mitos de la iconografía occidental como el de Penélope.

El discurso del exceso, de la subjetividad fragmentada de Tita, se aglutina en la redefinición del mito de Penélope, la tejedora. Como en el personaje de la Odisea, el tejido que Tita inicia desde el momento en que se promete con Pedro representa la fidelidad y la espera. Para ambos personajes, el tejido funciona entonces como un sustituto del amor ausente, si bien la función en ambas resulta especular: si Penélope deshace el tejido cada noche para prolongar la decisión de casarse con uno de sus muchos pretendientes, Tita teje compulsivamente desde la primera señal de ausencia de su único amor. La cualidad solitaria, nocturna, insomne, las unifica y les garantiza cierta forma de independencia. Para Penélope consiste en la voluntad intacta de no comprometerse, de negar la muerte de Ulises. Para Tita representa el calor amoroso que le falta, la voluntad de aferrarse a él y prolongar su ajuar de novia. El resultado en la segunda revierte en lo excesivo y dialógico: dada la variedad de estambre que utiliza Tita la colcha que teje se convierte en una enorme y caleidoscópica cola de novia cuando el doctor Brown la rescata de la severidad de la madre. La cola de novia se transfiere en sudario — como lo es propiamente el tejido de Penélope-, una vez que la colcha alcanza la extensión exacta del rancho materno.

En este punto difieren los dos postulados propuestos. Por una parte, Penélope está tejiendo y destejiendo en su condición de “otro” el discurso hegemónico del poder: aquel

12 "Re-vision -the act of looking back, of seeing with fresh eyes, of entering an old text from a new critical direction- is for women more than a chapter in cultural history: it is an act of survival" (35). 
representado por Laertes (a quien va dirigido el sudario), por Ulises (cuya vida simbólicamente viene mantenida por el tejido), por los pretendientes (por quienes Penélope idea la “trama”). Por otra, en Tita la proyección es personal, unívoca, diferenciada de lo "Uno”, y no implica el lamento sino la celebración. En el último encuentro amoroso de la novela, al tiempo que Tita consuma su amor con Pedro (también de forma unívoca, masturbatoria), consuma con su pasión las tres hectáreas de la extensión del rancho, esto es, el espacio del discurso oficial a quien vendría dirigido el sudario. Sólo un objeto se recupera de la acción redentora y purificadora: un libro de recetas que perpetúa y rescata de la autoridad patriarcal la identidad de la mujer mejicana. Esta identidad, que recupera en la escritura el espacio marginal y oral de la cocina, se celebra finalmente en un tejido también caleidoscópico de recetas, amores y remedios caseros, esto es, en la novela de entregas mensuales de Laura Esquivel. Con ella Tita de la Garza, tía abuela de la narradora, seguirá viviendo (persistiendo, subsistiendo, sin dejarse eliminar), mientras haya alguien que cocine, esto es, que lea, que interprete y que “consuma”, sus recetas.

\section{Bibliografía}

Castellanos, Rosario. “La mujer mexicana del siglo XIX”. Mujer que sabe latín .... México: Fondo de Cultura Económica, 1992. 159-65.

Como agua para chocolate (film). Alfonso Arau, director. Guión de Laura Esquivel. Con Lumi Cavazos, Marco Leonardi y Regina Torne (1992).

de Valdés, María Elena. "Verbal and Visual Representation of Women: Como agua para chocolate / Like Water for Chocolate". World Literature Today 69/1 (1995): 78-82.

Esquivel, Laura. Como agua para chocolate. Nueva York: Anchor Books, 1989. Like Water for Chocolate. Nueva York: Anchor Books, 1992.

Franco, Jean. Las conspiradoras. La representación de la mujer en México. México: Fondo de Cultura Económica, 1993.

Glenn, Kathleen M. “Postmodern Parody and Culinary-Narrative Art in Laura Esquivel's Como agua para chocolate”. Chasqui XXXI/2 (1994): 39-47.

Hutcheon, Linda. A Poetics of Postmodernism. History, Theory, Fiction. Londres: Routledge, 1992.

Ibsen, Kristine. “On Recipes, Reading and Revolution: Postboom Parody in Como agua para chocolate”. Hispanic Review 63/2 (1995): 133-45.

Jaffe, Janice. "Hispanic American Women Writers Novel Recipes and Laura Esquivel's Como agua para chocolate (Like Water for Chocolate)”. Women's Studies 22 (1993): 217-30.

Lawless, Cecilia. "Experimental Cooking in Como agua para chocolate”. Monographic Review 8 (1992): 261-72.

Leal, Luis. "Female Archetypes in Mexican Literature”. Women in Hispanic Literature. Icons and Fallen Idols. Beth Miller, ed. Los Angeles: University of California Press, 1983. 227-42.

Moliner, María. Diccionario de uso del español. Madrid: Ed. Gredos, 1966-1967.

Ordóñez, Elizabeth. "Sexual Politics and the Theme of Sexuality in Chicana Poetry". Women in Hispanic Literature. Icons and Fallen Idols. Beth Miller, ed. Los Angeles: University of California Press, 1983. 316-39. 
Paz, Octavio. El laberinto de la soledad. México: Fondo de Cultura Económica, 1991. Pirandello, Luigi. On humor. Chapel Hill: University of North Carolina Press, 1960.

Rich, Adrienne. "When We Dead Awaken: Writing as Re-vision”. On Lies, Secrets and Silence Nueva York: W.W.Norton, 1979.

Richter, David H. "Bakhtin". The Critical Tradition. Classic Texts and Contemporary Trends. Nueva York: Bedford Books, 1989. 724-26.

Valdés, María Elena de. "Verbal and Visual Representation of Women: Como agua para chocolate / Like Water for Chocolate”. World Literature Today 69/1 (1995): 78-82. 